\title{
Testing Impact of Commitment to Business Ethics Influences Corporation Performance: Preliminary Research
}

\author{
Silvija Vig \\ Polytechnic of Međimurje, Čakovec, Croatia \\ Ksenija Dumičić \\ Faculty of Economics and Business, Zagreb, Croatia
}

\section{Abstract}

Growing recognition of significance and the impact that commitment to business ethics has on corporate performance has attracted the interest of scientific and business researchers alike. At the same time, various stakeholders including boards, senior and corporate managers, employees, customers, suppliers, investors, governments and communities have been interested in the correlation between corporate performance in non-financial terms and its commitment to business ethics which has significantly increased its importance as well as its dominant impact in business. Research of the correlation of business ethics and business performance is widely conducted in the developed countries, yet it is still rare in Western Balkans countries, including Croatia, which gave rise to the need to conduct a survey on this topic. The paper comprises preliminary research which examines critical factors that present commitment to business ethics and their influence to non-financial performance indicators of the corporations. The paper also explores why and how the commitment to business ethics can contribute to the creation of corporate values that are eventually reflected in non-financial terms. The paper intends to give executives practical hands-on advice about the benefits of commitment to business ethics in a highly dynamic business environment today.

Keywords: Business Ethics, Commitment to Business Ethics, Corporate Performance, Non-financial Indicators

JEL classification: M14

Acknowledgments: This work has been fully supported by Croatian Science Foundation under the project STRENGTHS (project no. 9402).

\section{Introduction}

Even though the concept of business ethics has been presented throughout the whole history of doing business, in the late 1970s it has begun to institutionalise in business and academic world and has emerged as an interdisciplinary field which implies that more than forty years scientific and researchers studying the problems and phenomena of business ethics, and their influences and functions in the process of corporate governance and business performance. Nowadays, ethical business has emerged as an essential component in the long term business success and it is became an important issue in society, which give us a justified reason to explore its function in the corporate governance and performance of companies in modern market conditions.

Business ethics represents good or bad and right or wrong behaviour towards all stakeholders in business context and it deals with moral expectations and practices 
occurring in economic system. Social responsibility as the issue of external demonstration of ethical performance depends on internal organisational ethics based on in-depth ethical standards and an organisational culture that supports acting well. Therefore those principles through ethical standards need to become a part of every company. Although a large number of authors and researches denies beliefs of those who argue that ethics and business are excluded (Curcio, 2005), Trevino and Nelson (2010) define business ethics as a set of moral rules and values that influence and direct the behaviour of individuals or groups in relation to something what is right or wrong in making decisions and in the management. Therefore, many authors and entrepreneurs point out that business ethics improves business performance and provides operational excellence to every business person (Vujić et al., 2012).

\section{Previous research}

In the last decades, researchers spent a considerable amount of research on the topic on commitment of business ethics in the non-financial perspectives of corporate performance. While some authors, in terms of non-financial indicators, argue the ethics is a good business investment because it creates positive external impacts such as trust and commitment of the stakeholders which in turn guarantees the long term results (Webley et al., 2003, Hilman et al., 2001, Johnson et al., 1999), enhanced reputation and positive corporate image (Fombrun and Foss, 2004), increase customer loyalty (Garcia de los Salmones et al., 2009) and build competitive advantage (Fombrun et al., 2000), others are sceptical (e.g. Brammer et al., 2005). Berrone et al. (2005) shows that companies with strong ethical commitment achieve a higher degree of the stakeholder's satisfaction which ultimately has a stronger influence on financial result stated in market value added. Furthermore, in companies committed to business ethics employees' perception is positively related to job satisfaction (Martin and Cullen, 2006), trust in the organizations (Mulki et al., 2006), effective communication between managers and employees (Mulki et al., 2006) and ethical decision-making (Valentine and Barnett, 2007).

Based on the analysis of previous studies and limited studies that analyze the impact of business ethics in the non-financial perspectives of corporate performance in Western Balkans countries, including Croatia we conclude that there is a need for additional research on impact of business ethics on non-financial performance measured in terms of client satisfaction, human resources management and innovativeness and efficiency of business processes. Client and customer satisfaction present an important issue in evaluating company's performance which lead to trust and loyalty in long-term. Although the characteristics of human resource management are regarded to play significant roles in encouraging ethical organization, few empirical studies have been conducted (Wells and Schminke, 2001). Furthermore, there are very few studies examining the role of an organization's innovation in the contest of ethical organization (Gonzalez-Padron et al., 2008), therefore this study will suggest that an organization's innovation will be influenced by commitment to business ethics.

\section{Commitment to business ethics}

There are no standardized indicators and instruments that could measure the intension of organisational commitment to business ethics. Numerous authors have created set of indicators that differ in their criteria, but all have an aim to establish an ethical culture. Trevino et al. (1998) in their research used fourteen indicators in terms 
of leadership role modelling, ethics code, sanctions for ethical and unethical conduct and whether ethical behaviour is the norm in the company. Furthermore, Lloyd and Mey (2010) include in their model code of ethics, top management commitment, reward system, ethics training, helpline, whistle-blower protection, ethical assessment and audit and ethics committee. Additionally, there can be identified eleven dimensions as surrogate measures for ethical commitment including: top management support, culture, ethical leadership, open communication channels, ethics training, code of ethics, ethics hotline, ethics officers and ethics committees. It can be concluded that companies differ exactly depending on the values prevailing in an organisational culture and in the way of doing business inside an organization and towards all stakeholders in the system.

Based on previous research, in our study we determinate following indicators for measuring commitment to business ethics: motivation and rewarding policy for ethical behaviour and responding to unethical behaviour, communicating ethical values within the company, promoting an ethical culture, having an unambiguous, visible commitment and involvement in solving ethical problems by senior management, using ethical criteria in performance and efficiency evaluation of employees, using ethical criteria in risk assessment, implementing and integrating ethical criteria in organizational culture, using ethical criteria in corporate reporting to external stakeholders, selecting suppliers based on the standards of ethics and compliance and conducting due diligence in terms of ethics and compliance in mergers and acquisitions.

\section{Methodology}

Population of this research included all companies of Croatian economy. A list of companies from FINA (Croatian Financial Agency) database for 2014 was used as a sampling frame. The planned sample size was 600 companies. The total sample was equally allocated in large and medium companies, so the sample randomly included 300 medium and 300 large companies. Company size was determined by the classification of FINA where medium-sized companies have from 50 to 249 employees, and large have 250 or more employees. According to FINA in 2014 in Croatia, the total number of business entities amounted to 101,191, out of which 1,268 medium and 350 large companies. Due to the complexity of the criteria that determine commitment to business ethics, which do not appear widely in such a form in smaller companies, from the research was exempted small companies up to 49 employees.

Research instrument consisted of three sets of questions: (i) implementation of business ethics, (ii) non-financial perspectives of corporate performance, (iii) the demographics of subjects and companies. Questions were asked in the following forms: closed questions with selection of one or more predefined answers, questions where respondents expressed agreement with a particular statement using Likert scale and open-ended questions.

Data were collected in a way that the companies selected in the sample in the first phase, were contacted by telephone. In the next phase, the person was contacted via e-mail address, where also a questionnaire in electronic format was sent. Within the three months, a total of 100 completed questionnaires were collected (included 52 medium and 48 large companies). It should be noted that due to the specific topic, and the absence of a legal obligation to implement ethical program in Croatian companies, the return of the questionnaire of $16.67 \%$ for this survey is satisfactory. 


\section{Results}

In order to investigate the impact of ethics commitment to nonfinancial performance of the Croatian companies, multiple linear regression method has been used. Following independent variables were used:

- PE_l Motivation and rewarding policy for ethical behaviour and responding to unethical behaviour

- PE_2 Communicating ethical values within the company

- PE_3 Promoting an ethical culture, having an unambiguous, visible commitment and involvement in solving ethical problems by senior management

- PE_4 Using ethical criteria in performance and efficiency evaluation of employees

- PE_5 Using ethical criteria in risk assessment

- PE_6 Implementing and integrating ethical criteria in organizational culture

- PE_7 Using ethical criteria in corporate reporting to external stakeholders

- PE_8 Selecting suppliers based on the standards of ethics and compliance

- PE_9Conducting due diligence in terms of ethics and compliance in mergers and acquisitions

Three regression models were developed using following dependent variables:

- Client satisfaction, that was calculated as the average value of three variables CF_1 (Customer satisfaction), CF_2 (Market share) and CF_3 (Quality of products and services)

- Human resources management, that was calculated as the average value of three variables HR_1 (Employee productivity), HR_2 (Employee loyalty) and HR_3 (Employee turnover)

- Innovativeness and efficiency of business processes, that was calculated as the average value of three variables IE_l (The efficiency of internal processes), IE_2 (Innovation of products and services) and IE_3 (Internal processes innovation)

Table 1 represents the regression model with the dependent variable Client satisfaction, and independent variables PE_1 to PE_9, which indicate ethics commitment. The results revealed that the following variables have statistically significant impact:

- PE_l (Motivation and rewarding policy for ethical behaviour and responding to unethical behaviour) has a positive statistically significant impact to the Client satisfaction at $10 \%$

- PE_8 (Selecting suppliers based on the standards of ethics and compliance) has a positive statistically significant impact to the Client satisfaction at $5 \%$

Model explains $26.2638 \%$ of the variability of the dependent variable Client satisfaction. Heteroscedasticity is not present (White's test LM $=52.2621$; BreuschPagan $L M=1.86902$ ), and that residuals are normally distributed ( $p$-value $=0.157167$ ). 
Table 1

Regression model with the dependent variable Client satisfaction

\begin{tabular}{|c|c|c|c|c|}
\hline & $\begin{array}{c}\text { Coefficien } \\
t\end{array}$ & Std. Error & t-ratio & p-value \\
\hline const & 2,25794 & 0,256823 & 8,7918 & $<\underset{*}{<0,00001^{* *}}$ \\
\hline$p e_{-} 1$ & 0,165324 & 0,0978315 & 1,6899 & $0,09451^{*}$ \\
\hline pe_2 & $-0,0276695$ & 0,127234 & $-0,2175$ & 0,82833 \\
\hline pe_3 & 0,0141224 & 0,109232 & 0,1293 & 0,89742 \\
\hline pe_4 & 0,015444 & 0,141952 & 0,1088 & 0,91361 \\
\hline pe_5 & $-0,196606$ & 0,145599 & $-1,3503$ & 0,18030 \\
\hline $\mathrm{pe} \_6$ & 0,172202 & 0,134153 & 1,2836 & 0,20257 \\
\hline pe_7 & 0,00642077 & 0,104182 & 0,0616 & 0,95099 \\
\hline pe_8 & 0,342048 & 0,135728 & 2,5201 & $0,01349 * *$ \\
\hline pe_9 & $-0,040798$ & 0,122522 & $-0,3330$ & 0,73992 \\
\hline $\begin{array}{l}\text { Adjusted R- } \\
\text { squared }\end{array}$ & & & & 0,262638 \\
\hline
\end{tabular}

Notes: ${ }^{*}$ statistically significant at $10 \% ;{ }^{* *} 5 \%$; ${ }^{* *} 1 \%$

Source: Authors

Table 2 shows the regression model with the dependent variable Human resources management, and independent variables PE_1 to PE_9, which indicate ethics commitment. The results revealed that the following variables have statistically significant impact:

- PE_l (Motivation and rewarding policy for ethical behaviour and responding to unethical behaviour) has a positive statistically significant impact to the Human resources management at $1 \%$

Model explains $31.6860 \%$ of the variability of the dependent variable Human resources management. Heteroscedasticity is not present (White's test $L M=48.4853$; Breusch-Pagan $L M=12.0142$, and that residuals are normally distributed ( $p$-value = 0.962229).

Table 2

Regression model with the dependent variable Human resources management

\begin{tabular}{|l|c|c|c|c|}
\hline & Coefficient & Std. Error & t-ratio & $p$-value \\
\hline const & 2,00293 & 0,229402 & 8,7311 & $<0,00001^{* * *}$ \\
\hline pe_1 & 0,26669 & 0,0873858 & 3,0519 & $0,00299^{* * *}$ \\
\hline pe_2 & 0,165291 & 0,113649 & 1,4544 & 0,14931 \\
\hline pe_3 & $-0,0775438$ & 0,0975687 & $-0,7948$ & 0,42884 \\
\hline pe_4 & $-0,0627676$ & 0,126796 & $-0,4950$ & 0,62179 \\
\hline pe_5 & $-0,104987$ & 0,130053 & $-0,8073$ & 0,42164 \\
\hline pe_6 & 0,146953 & 0,119829 & 1,2264 & 0,22327 \\
\hline pe_7 & 0,0504204 & 0,0930583 & 0,5418 & 0,58928 \\
\hline pe_8 & 0,0447339 & 0,121236 & 0,3690 & 0,71301 \\
\hline pe_9 & 0,00592909 & 0,10944 & 0,0542 & 0,95691 \\
\hline Adjusted R-squared & & & & 0,316860 \\
\hline
\end{tabular}

Notes: ${ }^{* * *}$ statistically significant at $1 \%$

Source: Authors 
Table 3 presents the regression model with the dependent variable Innovativeness and efficiency of business processes, and independent variables PE_1 to PE_9, which indicate ethics commitment. The results revealed that the following variables have statistically significant impact:

- PE_l (Motivation and rewarding policy for ethical behaviour and responding to unethical behaviour) has a positive statistically significant impact to the Innovativeness and efficiency of business processes at $5 \%$

- PE_4 (Using ethical criteria in performance and efficiency evaluation of employees) has a positive statistically significant impact to the Innovativeness and efficiency of business processes at $10 \%$

Model explains $37.2777 \%$ of the variability of the dependent variable Innovativeness and efficiency of business processes. Heteroscedasticity is not present (White's test LM = 62.2024; Breusch-Pagan LM = 5.95911), and that residuals are normally distributed ( $\mathrm{p}$-value $=0.566927$ ).

Table 3

Regression model with the dependent variable Innovativeness and efficiency of business processes

\begin{tabular}{|l|c|c|c|c|}
\hline & Coefficient & Std. Error & t-ratio & p-value \\
\hline const & 1,36935 & 0,287453 & 4,7637 & $<0,00001^{* * *}$ \\
\hline pe_1 & 0,237938 & 0,109499 & 2,1730 & $0,03241^{* *}$ \\
\hline pe_2 & 0,0451613 & 0,142408 & 0,3171 & 0,75188 \\
\hline pe_3 & $-0,180842$ & 0,122259 & $-1,4792$ & 0,14259 \\
\hline pe_4 & 0,27172 & 0,158882 & 1,7102 & $0,09067^{*}$ \\
\hline pe_5 & $-0,0284393$ & 0,162964 & $-0,1745$ & 0,86185 \\
\hline pe_6 & 0,0837863 & 0,150153 & 0,5580 & 0,57823 \\
\hline pe_7 & $-0,064877$ & 0,116607 & $-0,5564$ & 0,57934 \\
\hline pe_8 & 0,195979 & 0,151915 & 1,2901 & 0,20034 \\
\hline pe_9 & 0,0417804 & 0,137135 & 0,3047 & 0,76132 \\
\hline $\begin{array}{l}\text { Adjusted } \\
\text { squared }\end{array}$ & & & & 0,372777 \\
\hline
\end{tabular}

Notes: ${ }^{*}$ statistically significant at $10 \% ;{ }^{* *} 5 \% ;{ }^{* * *} 1 \%$

Source: Authors

\section{Conclusion}

This study tested correlation between commitment to business ethics and objective of non-financial performance such as client satisfaction, human resources management and innovativeness and efficiency of business processes, by using measures of aggregated employees' perceptions. The empirical results of the regression model show that certain dimension of commitment to business ethics had a positive influence on non-financial performance of the companies. Moreover, we found that motivation and rewarding policy for ethical behaviour and responding to unethical behaviour as a dimension of commitment to business ethics has distinctive effects on all three non-financial performance indicators (client satisfaction, human resources management and innovativeness and efficiency of business processes). We also found that selecting suppliers based on the standards of ethics and compliance had a positive and strong influence on client satisfaction, considering the fact that client and customers' satisfaction continue to make the most important component for long-term performance success of the company, this present a 
significant issue. We confirmed the positive and significant influence of using ethical criteria in performance and efficiency evaluation of employees on innovativeness and efficiency of business processes as a dimension of non-financial performance of the companies, as well.

When evaluating the results of this work it is necessary to consider that the data are used for 100 Croatian companies that participated in the survey which may be a limitation. Thus, future research with enlarged sample in more developing countries is needed to examine whether the results of this study would hold.

However, the results of the study have theoretical and practical content and they are useful for scientific and business researchers alike in several way. First of all, this study proves that a certain dimension of commitment to business ethics increase non-financial performance through examining such relationship at the individual level. Secondly, this study provides practical implications for companies in developing countries such as Croatia by showing that a commitment to business ethics can be an important predictor of non-financial performance as well as a client satisfaction, human resources management and innovativeness and efficiency of business processes. Thirdly, this paper confirmed that ethics and business go simultaneously in modern economy. Our work provides evidence that doing the right thing is lastly the organization's best interest. It represents that business ethics provides greater degree of client and employees 'satisfaction which in the long term result in loyalty for both categories and higher productivity in terms of employees. Conclusively, this research, as a preliminary research can be a starting point for further research in other developing countries, such as Western Balkans countries.

\section{References}

1. Berrone, P., Surroca, J., Tribó, J. A. (2007), "Corporate ethical identity as a determinant of firm performance: A test of the mediating role of stakeholder satisfaction". Journal of Business Ethics, Vol. 76 No. 1, pp. 35-53.

2. Brammer, S., Pavelin, S. (2005), "Corporate community contributions in the United Kingdom and the United States" Journal of Business Ethics, Vol. 56 No. 1, pp. 15-26.

3. Curcio, R. (2005), "Etička klopka" ["The Ethic Trap"], TIM press, Zagreb.

4. Fombrun, C., Foss, C. (2004), "Business ethics: Corporate responses to scandal", Corporate Reputation Review, Vol. 7 No. 3, pp. 284-288.

5. Fombrun, C. J., Gardberg, N. A., Barnett, M. L. (2000), "Opportunity platforms and safety nets: Corporate citizenship and reputational risk", Business and society review, Vol. 105 No. 1, pp. 85-106.

6. García de los Salmones, M. M., Perez, A., Rodríguez del Bosque, I. (2009), "The social role of financial companies as a determinant of consumer behaviour", International Journal of Bank Marketing, Vol. 27 No. 6, pp. 467-85.

7. Gonzalez - Padron, T., Hult, G. T. M., Calantone, R. (2008), "Exploiting innovative opportunities in global purchasing: An assessment of ethical climate and relationship performance", Industrial Marketing Management, Vol. 37 No. 1, pp. 69-82.

8. Hillman, A. J., Keim, G. D. (2001), "Shareholder value, stakeholder management, and social issues: what's the bottom line?", Strategic management journal, Vol. 22 No. 2, pp. 125-139.

9. Johnson, R. A., Greening, D. W. (1999), "The effects of corporate governance and institutional ownership types on corporate social performance", Academy of Management Journal, Vol. 42 No. 5, pp. 564-576.

10. Lloyd, H. R., Mey, M. R. (2010), "An ethics model to develop an ethical organisation: original research", SA Journal of Human Resource Management, Vol. 8 No. 1, pp. 1-12.

11. Martin, K. D., Cullen, J. B. (2006), "Continuities and extensions of ethical climate theory: A meta-analytic review", Journal of Business Ethics, Vol. 69 No. 2, pp. 175-194. 
12. Mulki, J. P., Jaramillo, F., Locander, W. B. (2006), "Effects of ethical climate and supervisory trust on salesperson's job attitudes and intentions to quit", Journal of Personal Selling \& Sales Management, Vol. 26 No. 1, pp. 19-26.

13. Treviño, L. K., Nelson, K. A. (2010), "Managing business ethics", John Wiley \& Sons.

14. Treviño, L. K., Butterfield, K. D., McCabe, D. L. (1998), "The ethical context in organizations: Influences on employee attitudes and behaviours", Business Ethics Quarterly, Vol. 8 No. 03, pp. 447-476.

15. Valentine, S., Barnett, T. (2007), "Perceived organizational ethics and the ethical decisions of sales and marketing personnel", Journal of Personal Selling \& Sales Management, Vol. 27 No. 4, pp. 373-388.

16. Vujić, V., Ivaniš, M., Bojić, B. (2012), "Poslovna etika i multikultura ["Business Ethics and Multiculturalism"], Fakultet za menadžment u turizmu i ugostiteljstvu, Opatija.

17. Webley, S., More, E. (2003), "Does business ethics pay", Ethics and Financial.

18. Wells, D., Schminke, M. (2001), "Ethical development and human resources training: An integrative framework", Human Resource Management Review, Vol. 11 No. 1, pp. 135158.

\section{About the authors}

Silvija Vig is a Lecturer at the Polytechnic of Međimurje, Čakovec and at the Academy of Dramatic Art -Zagreb. Now she attends post-graduate doctoral study at the Faculty of Economics and Business - Zagreb. Her main research fields include business ethics, ethical organisational culture and leadership. The author can be contacted at silvija.vig@mev.hr

Ksenija Dumičić is a Full Professor with Tenure at the Department of Statistics, Faculty of Economics and Business, University of Zagreb. Her main research fields include sampling, statistics, business statistics, sampling for social and business surveys. The author can be contacted at kdumicic@efzg.hr 